[ CONNECTING EMPloyers, EDUCATIONAL Institutions, AND WORKERS $]$

\title{
Transitioning Workers from Coal to Other Careers:
}

Hiring Our Miners Everyday (HOME) Program
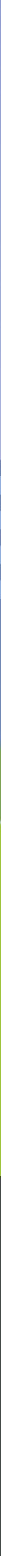

CASE STUDY 5 


\section{Overview}

Despite a long-term decline in coal mining employment, eastern Kentucky has found recent job losses especially troublesome to a region that historically has relied on the coal industry as an economic engine. According to the Kentucky Energy Database, coal mining employment in eastern Kentucky fell from approximately 67,000 workers in 1950 to about 15,000 workers in 2000 , when it appeared to stabilize until 2011 (see Figure 2). Then another steep decline hit. Over the next three years, one out of every two coal miners lost his or her job as coal miner employment fell to roughly 7,000 workers in 2014 . The economic loss to the region over those few years is staggering. A very rough estimate $-8,000$ jobs lost at $\$ 72,000$ a year-is $\$ 576$ million, or more than half a billion dollars of potential local spending and taxable income lost in an already economically depressed region.

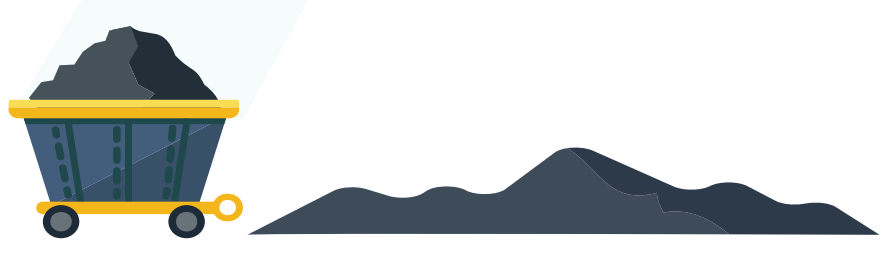




\section{Unlike the other workforce development programs we examined, $H O M E$ is a retraining program that helps direct workers out of a specific industry rather than into one.}

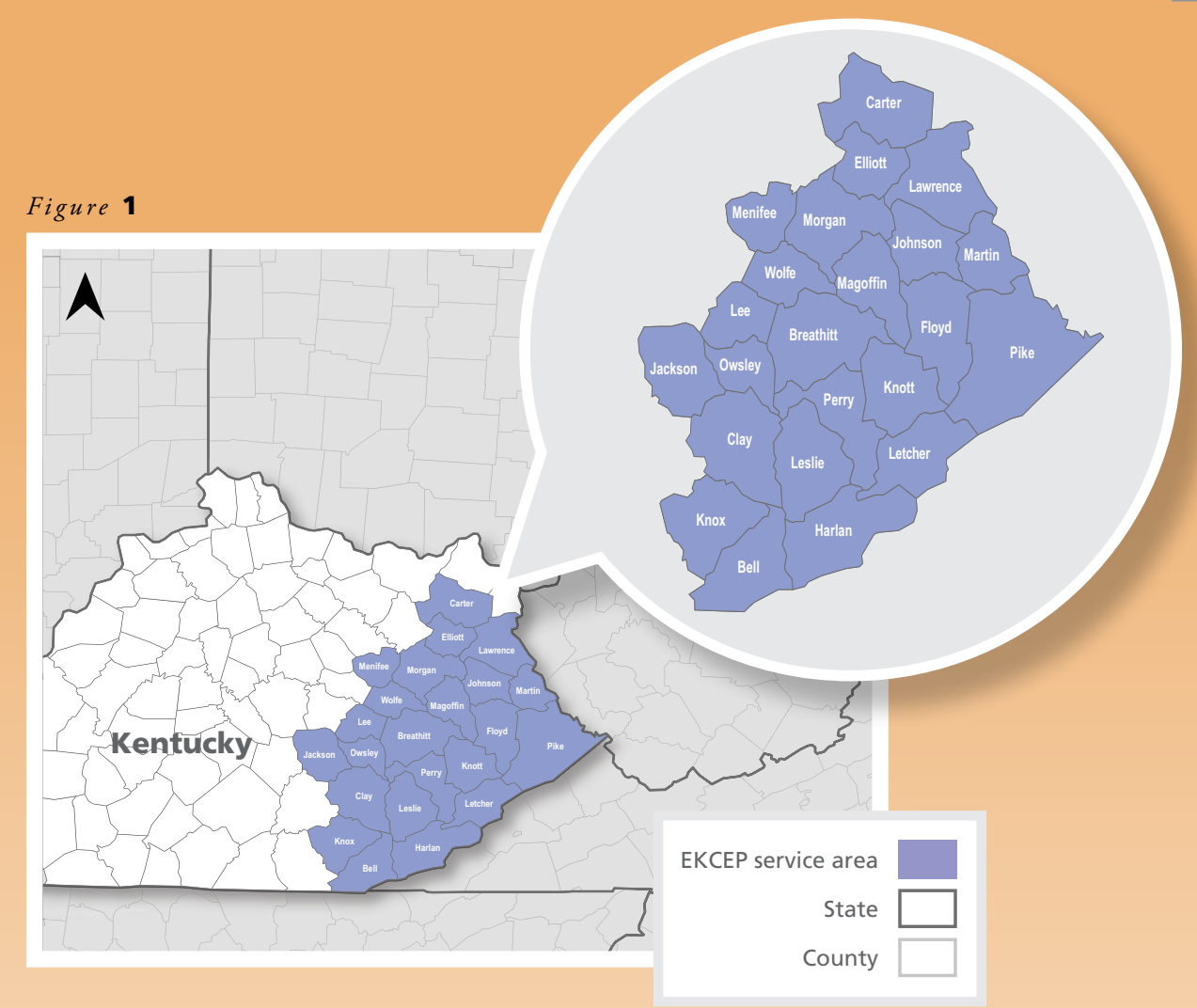

The cyclicality of employment levels in the coal industry is as old as the industry itself and has become part of being a coal miner. Unfortunately, it appears that this time is different and mining employment will not bounce back as it has in the past. Industry and policy reports ${ }^{1,2}$ indicate that these coal jobs will not return because of the pending closing of older coal-fired power plants that have become too costly to operate, along with moves at the federal and state levels to diversify energy portfolios. Increasing concerns around climate change also present a challenge for coal miners looking to return to the mines. These economic realities warranted significant action to find ways to retrain and re-employ former coal miners in the region.
One effort to help address the decline of coal mining employment in eastern Kentucky was funding the Hiring Our Miners Everyday (HOME) program. In 2013, the U.S. Department of Labor awarded an initial \$5.1 million National Emergency Grant to the Eastern Kentucky Concentrated Employment Program, Inc. (EKCEP) to fund its HOME program, an effort aimed at helping workers and their spouses affected by the coal industry downturn. Unlike the other workforce development programs we examined, HOME is a retraining program that helps direct workers out of a specific industry rather than into one. According to EKCEP, which administers 


\section{Eastern Kentucky coal employment}

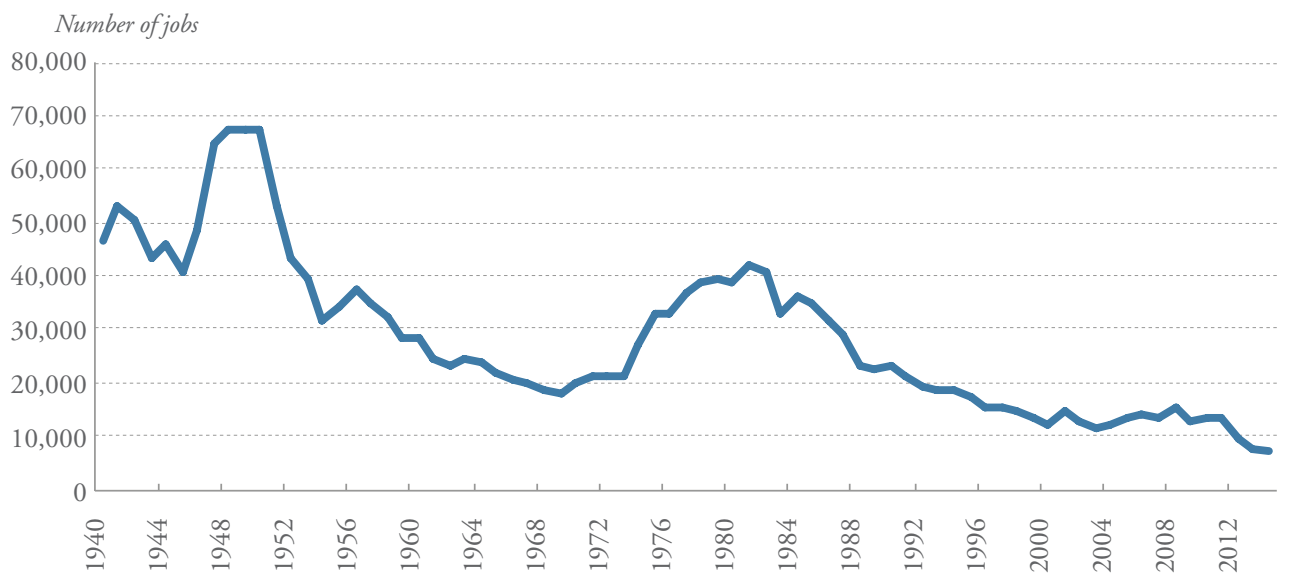

Source: Kentucky Energy Database.

the program, HOME helps coal mining workers "discover their skills, determine new career options, covers costs for them to enter classroom training, and helps place them into subsidized on-the-job training positions with area employers." Since the Labor Department's initial grant, an additional $\$ 8.9$ million has been directed to the program as employment losses in the coal industry continued.

While the HOME program is not a conventional sectorbased training program, it features many elements similar to traditional industry partnerships, including strong relationships with local institutions. In a way, HOME functions as a training program for the eastern Kentucky region itself, transitioning workers from a declining industry into roles that contribute to making the region more productive for future industries. Insights from EKCEP's HOME program are informative to economic and workforce development professionals looking to partner with diverse groups for the betterment of a local economy and its people.

\section{Structure}

Prior to implementing HOME in 2013, EKCEP had in place many of the relationships necessary for the program's success. EKCEP was formed in 1968 under the federal Manpower Development and Training Act to address the job training needs of the chronically unemployed and those living in severe poverty. In its 23-county service area (see Figure 1) in rural, mountainous eastern Kentucky, EKCEP offices house the local JobSight career center at which job seekers can access state and federal programs for training assistance. With almost 50 years of operation, EKCEP and its traditional partners in the workforce development system (including the Office of Employment and Training, the Office of Adult Education, and the Office of Vocational Rehabilitation), social services (including local community action groups), and local community college system provided a solid foundation from which to operate the HOME program.

EKCEP also works with local employers to address their workforce needs. Its in-house employer services team provides a multitude of services-from recruiting and screening of candidates, hosting job fairs, and providing labor market information to facilitating contact with state and federal workforce programs, working with training providers to customize curriculum, and delivering soft-skills training — to help regional employers meet their workforce needs. 


\section{HOME functions as a training program for the eastern Kentucky region itself, transitioning workers from a declining industry into roles that contribute to making the region more productive for future industries.}

Despite longstanding relationships with employers, EKCEP found it a difficult prospect to help re-employ coal miners given the limited employment opportunities in the region. In order to increase opportunities, EKCEP partnered with other organizations on new efforts promoting economic development activities in the eastern Kentucky region. The Shaping Our Appalachian Region (SOAR) initiative was formed in 2013 to promote and support job creation, innovation, opportunity, and quality of life in eastern Kentucky. As a result of early and frequent interactions with this group, Jeff Whitehead, executive director at EKCEP, was asked by Kentucky's then-Governor Steve Beshear to serve as the chair for the Education and Retraining Committee of SOAR. This role elevated EKCEP's status in the region as well as the plight of the coal miners, while helping to align the political capital to move the region forward.

More recently EKCEP has formed relationships with those involved with One East Kentucky, a strategy implemented by the Southeast Kentucky Chamber of Commerce and local businesses to create 2,500 jobs that meet or exceed the state's average annual wage $(\$ 42,000)$ while generating $\$ 30$ million in capital investment in the region. From the perspective of those involved with One East Kentucky, supporting and collaborating with local workforce development partners is necessary because the quality of an area's workforce helps attract and retain businesses. From EKCEP's perspective, its agency's support of and collaboration with economic developers is needed in order to find avenues to re-employment. Chuck Sexton, chief executive officer of One East Kentucky, noted in interviews for this case study that this "symbiotic relationship" is already beginning to bear fruit in the form of a commissioned study to document the diverse skill sets present across the region.

HOME participants are eligible for a comprehensive array of workforce development services in addition to receiving education and training funds. Kentucky's career center networks utilize the same career advising approach for helping ex-coal miners gain employment that is used for regular job seekers. Their customizable approach to the job search helps to identify, target, and find jobs that align with a job seeker's skill set.
Office

of Employment and Training

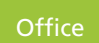

of Adult

Education
Office of

Vocational

Rehabilitation
Local

Community

College System
Local

Community Action Groups

\section{EKCEP}


Figure 4 lists many of the career and training services available to job seekers through the HOME program. While most of these are standard services offered in workforce development centers across the country, EKCEP singled out job clubs as one of the most important services it offers. With weekly group meetings, the job clubs operate not only as an informal entry into the HOME program, but also as a support group and network for job seekers. The group meetings let people know they are not the only ones looking for a job, while creating an environment for career advisors to get to know each job seeker a little better.

The HOME program also helps cover costs associated with upgrading skills. Once participants are accepted into a training program at a local community college,
HOME covers tuition along with supplies and tools needed to complete the program. The HOME program also incentivizes local employers in the region to hire former coal miners by paying a significant portion of on-the-job training wages for qualified workers.

Laid-off coal miners and their spouses are eligible for these services as well as others included in the HOME program. In many households, two adults need to work to earn the equivalent of one paycheck from a coal industry position. In 2014, the average annual wage for a coal miner in Kentucky was $\$ 72,000$, compared to $\$ 42,000$ for all other workers in the state, according to the Quarterly Census for Employment and Wages.

\begin{tabular}{|c|c|} 
Figure 4 & \\
\hline Career Services & Training Service \\
\hline Generic resume assistance & Career advising \\
\hline Job search & Case management \\
\hline Job matching and referral & Individualized Plan for Employment (IPE) \\
\hline Access to labor market information & Individualized Education Program (IEP) \\
\hline In-depth skills assessment & Targeted resume/cover letter \\
\hline Basic skills instruction & Interview coaching \\
\hline Remediation & Job coaching \\
\hline Job clubs & Job retention skills \\
\hline Workshops & Short-term, long-term, and on-the-job training \\
\hline Veterans assistance & Paid internships and work experience \\
\hline
\end{tabular}




\section{EKCEP singled out job clubs as one of the most important services it offers. With weekly group meetings, the job clubs operate not only as an informal entry into the HOME program, but also as a support group and network for job seekers.}

\section{Successes and obstacles}

With most of the pieces in place to retrain and subsequently re-employ laid-off coal miners, the HOME program appears to have little that is standing in the way of its success. This may be a result in part of EKCEP's overcoming several major obstacles it encountered in developing the programobstacles that, interestingly, have become influential to the HOME program's success.

\section{FUNDING}

The HOME program had to overcome at least one substantial obstacle to obtain Department of Labor grants. The funding protocol required the grant seeker to specify prior to receiving the funds the companies from which workers had been laid off. According to EKCEP staff, the model for the Labor Department grants is based on closings in urban areas where the employers of soon-to-be-laid-off workers are known beforehand and can be listed on the grant application. While this model generally works well for a traditional plant or factory closing, it applies poorly to the situation in eastern Kentucky because little to no notification was given by coal companies prior to the latest round of layoffs. EKCEP staff noted that it was challenging to contact laid-off workers; when notified of the impending layoffs, many employees simply left the workplace and did not return. This quirk of the coal industry in rural eastern Kentucky required EKCEP staff to be flexible in order to overcome this funding obstacle.

\section{PERSISTENT REGIONAL CHALLENGES}

The major challenge to putting ex-coal miners back to work is the region's slow-growing economy. According to EKCEP staff, economic development in the region was tough even before the latest coal downturn.
In addition to the loss of coal-mining jobs, the region suffered substantial indirect job loss with the industry downturn; according to EKCEP staff an estimated three additional jobs are lost for every one coal job that is eliminated. There simply are not enough jobs for everyone. Not only does the lack of jobs present an economic challenge, but balancing the expectations of long-term projects and uncertainty with the short-term needs of the local people can also be a challenge.

Another challenge is the sense of parochialism that historically has been an obstacle to the implementation of programs in the region. However, with the creation of SOAR and One East Kentucky, it appears that local governments have begun to understand that because markets do not recognize boundaries, they must work together for the greater good of the region. Chuck Sexton, chief executive officer of One East Kentucky, stated that one way to continue addressing parochialism in the region is "making sure that we can put together some comprehensive local incentive packages" that do not pit one part of the region against another. This ability to think more regionally about the future has also helped to draw the interest of the region's younger population. According to Jeff Whitehead, this demographic's involvement is important because "this generation is quite talented and full of new ideas to help move the region forward." 


\section{PROGRAM PARTICIPANTS}

One of the biggest obstacles encountered in the HOME program was the coal miner mindset, which in turn may actually be the workers' greatest asset in HOME's efforts to getting them re-employed. The coal miner mindset refers to how the job of a coal miner is much more than just a job: It's an identity. Director Whitehead explains the coal miner mindset:

\section{"I'm a coal miner. I define myself as a}

coal miner. That's who I am, that's what

I do, this is my way of life. My father was

a coal miner, my grandfather was a coal

miner, my great-grandfather was a coal miner.

I get up in the morning before daylight. I work.

This is what I do. Now all of a sudden you are

telling me I am not a coal miner anymore.

It's a way of life more than just what I do to

make money. I have been through this before.

I've been laid off before. This is part of my

identity. You get laid off; you weather the storm.

You do it again. Layoffs are part of my business."
Addressing this mindset required getting coal miners to see that this downturn is permanent; unlike previous down cycles, the jobs are not returning. This was not a simple task. Acceptance of this fact was even more difficult for the former coal miners because of the relatively higher wages paid by the coal industry versus the pay of employment options in other industries.

Once former coal miners accept this fate, EKCEP's career services team helps them to identify skills they have that are transferrable. Jeff Whitehead describes the HOME program as "reinventing who we are, without losing who we are." According to EKCEP staff we interviewed, former coal workers have attributes from having worked in the mines- they are dependable, safety-conscious team members, for one-that make them highly attractive to potential employers. "Many have a very good work ethic and very good mechanical and technical skills," added Dr. Jennifer Lindon, the current president of Hazard Community and Technical College and its former dean of Occupational Technologies and Workforce Solutions. "We just have to retrain them."

It appears to be working. As of March 2016, the HOME program has enrolled more than 3,000 laid-off coal miners and their spouses. Of those enrolled, 1,449 have received support while training for new careers. More than 1,100 have obtained new employment, while 90 participated in internships through the HOME program. Feedback from employers who are hiring workers who have been through the HOME program has been positive, too; EKCEP staff have heard "universally rave reviews about coal industry workers." 


\section{According to EKCEP staff we interviewed, former coal workers have attributes from having worked in the mines-they are dependable, safety-conscious team members, for one-that make them highly attractive to potential employers.}

The former coal workers are finding roles in a range of industries new to them. The electrical lineman program with Hazard Community and Technical College, for example, has been one of the most successful at retraining coal miners. The fall 2015 program was the fifth class to include HOME participants. Thus far through five cohorts, 124 laid-off coal miners have gone through the program, earning portable industry-recognized credentials (CDL class A, CPR, OSHA) and gaining 10 weeks of industry-based lineman instruction. An additional fiberoptic certification is also offered through the program in anticipation of a state-wide broadband installation program. The lineman program job-placement rate is 91 percent; however, not all of those placements are in the region. Many graduates travel outside the region for work during the week and return on the weekends. Demand for the electrical lineman program is high (there is a two-semester waiting list) because students exiting the program earn, on average, $\$ 20$ per hour.

Bit Source is another example of the HOME program's success in partnering with employers to retrain and find new employment for former coal miners. Bit Source is a unique entrepreneurial for-profit technology company helping the eastern Kentucky region transition from coal exports to computer code exports. Recognizing that contemporary coal-mining operations require high-skilled workers to operate some of the largest and most complex machines in the world, Bit Source approached EKCEP with a plan to set up a pilot training program to take the workforce "from coal to code." Initial demand suggests there is potential for this program; almost 900 people applied for the ten initial training slots, according to EKCEP staff, with nine of the slots going to former coal industry workers.

\section{PARTNERS}

In order to increase the amount of potential employment opportunities for HOME participants, EKCEP needed to reach out to new partners in the economic development community. In describing how EKCEP has worked to develop these new relationships, Jeff Whitehead said, "You develop relationships by saying yes to a lot of people and being willing to travel. That's part of how we've changed. We are physically going to meetings so much more." The face-to-face contact in meetings has been essential to EKCEP's ability to develop relationships and ultimately build trust. "You move at the speed of trust," observed Whitehead. "Trust has to be built." 


\section{Conclusion}

\section{$\times$}

A unique program to retain and retrain former coal workers, the HOME program is helping position workers and the eastern Kentucky region for success in other industries.
Despite the depressed economic conditions of the eastern Kentucky region, there are reasons to be optimistic about the future. Sources of optimism include the manner in which the community responded to the crisis, the early successes of the HOME program, and the potential for economic development in the region. Early evidence suggests that EKCEP and its many partners are using the HOME program to lay the groundwork for future economic growth.

Though devastating and painful, the recent layoffs in eastern Kentucky's coal industry prompted community actions that have helped to position the region for future growth. The creation of SOAR and One East Kentucky, for example, provides a lot of complementary momentum in the region. The alignment of goals and strategic decision making across the region signal that the tendency for parochialism in the region is waning.

On a broad level, the early successes of the HOME program illustrate the collaboration and coordination necessary to successfully implement major workforce development programs. More specifically, the HOME program is showing how coal industry workers can be retrained to work in new industries.

Author Kyle Fee is a Regional Community Development Advisor at the Federal Reserve Bank of Cleveland. 
Authors: Kyle Fee, Matthew Klesta, and Lisa Nelson, Federal Reserve Bank of Cleveland

Published by the Federal Reserve Bank of Cleveland's Community Development Department.

The views expressed in this publication are those of the authors; these views do not necessarily reflect those of the Federal Reserve Bank of Cleveland, the Federal Reserve Board of Governors, or the Federal Reserve System. Reprinting allowed with permission; contact Managing Editor Anne O'Shaughnessy at Anne.oshaughnessy@clev.frb.org.

Members of the Cleveland Fed Community Development Department include

\section{CLEVELAND}

Paul Kaboth

Vice President \&

Community Development Officer

216.579.2951

Paul.kaboth@clev.frb.org

Mary Helen Petrus

Assistant Vice President

216.579.2443

Mary.h.petrus@clev.frb.org

Brett Barkley

Research Analyst

216.206.3658

Brett.barkley@clev.frb.org

Kyle Fee

Regional Community

Development Advisor

216.579.2029

Kyle.d.fee@clev.frb.org

Matthew Klesta

Policy Analyst

216.579.3166

Matthew.klesta@clev.frb.org

Hal Martin

Policy Economist

216.774.2526

Hal.martin@clev.frb.org

Lisa Nelson

Community Development Advisor 216.579.2903

Lisa.a.nelson@clev.frb.org

Anne O'Shaughnessy

Communications Advisor

216.579.2233

Anne.oshaughnessy@clev.frb.org

Ann Marie Wiersch

Senior Policy Analyst

216.579.2423

Annmarie.wiersch@clev.frb.org
PITTSBURGH

Joseph Ott

Regional Community

Development Advisor

412.261 .7947

Joseph.c.ott@clev.frb.org

CINCINNATI

Bonnie Blankenship

Regional Community

Development Advisor

513.455.4281

Bonnie.blankenship@clev.frb.org
CONNECT WITH THE CLEVELAND FED 
www.clevelandfed.org/communitydevelopment 